\title{
Method to Support Circular Economy of aggregates (Sand / Gravel)
}

\author{
Ginevra Balletto ${ }^{*}$, Filippo Carlo Pavesi ${ }^{2}$, Anna Richiedei ${ }^{2}$ and Michèle Pezzagno ${ }^{2}$ \\ 1 Department of Civil and Environmental Engineering and Architecture. University of Cagliari, Italy \\ balletto@unica.it \\ ${ }^{2}$ Department of Civil, Environmental, Architectural Engineering and Mathematics. University of Brescia, Italy; \\ filippo.pavesi@unibs.it; anna.richiedei@unibs.it; michele.pezzagno@unibs.it \\ * Correspondence: balletto@unica.it;
}

Citation: Balletto, G.; Pavesi, F.C.; Richiedei, A.; Pezzagno, M.,2022, Method to Support Urban Planning for circular economy of aggregates (Sand/Gravel). SUPTM 2022 conference proceedings sciforum054469.

https://doi.org/10.31428/10317/10603

Publisher's Note: UPCT and Sciforum stays neutral with regard to jurisdictional claims in published maps and institutional affiliations.

Copyright: (c) 2022 by the authors. Submitted for possible open access publication under the terms and conditions of the Creative Commons Attribution (CC BY) license (https://creativecommons.org/license s/by/4.0/).

\begin{abstract}
The objectives of the Green Deal require new circular economy approaches also starting from the management of construction and demolition waste. Circularity processes are affected both by regulatory actions and by physical, urban and industrial geographical aspects. The processes of industrial circularity are inserted in the territory where linear economies already exist by hybridizing them. In fact, localization processes of circular economies present cluster configurations. Furthermore, these circular economies are configured differently in relation to physical geography, to urban centers and transport infrastructures. The paper therefore aims to evaluate two case studies to extrapolate the risks and opportunities of the circular economy from construction and demolition waste (CDW).
\end{abstract}

Keywords: circular economy; spatial planning support system; geographic information system;

\section{Introduction}

The Legislative Decree n. 121 of 3 September 2020, which amends and integrates the complex regulatory provision on waste, intends to pursue a progressive reduction in landfilling of waste, in particular those suitable for recycling or other types of recovery, in order to support the transition to a circular economy. This new legislation will significantly affect the management of construction and demolition waste (CDW) in the construction market, which constitutes $48 \%$ of the total waste production in Italy [1] allowing their transformation into new products [2]. In this framework, the paper proposes the evaluation of two realities (Region of Sardinia and Province of Brescia) in which the aggregate market is relevant, but different for physical and anthropogenic geographies. In particular, the region of Sardinia can be considered closed, while that of the province of Brescia is open. The two case studies present different levels of quarry planning and legislation (sand and gravel). At the regional level for Sardinia, at the provincial level for Brescia. The peculiarities of each reality examined with the aim of identifying and verifying the presence of clustering conditions useful for supporting circular economy mechanisms will be illustrated below. The following is an analysis of the information available regarding the natural aggregate (NA) and recycled aggregate (RA) supply for the territory of the Sardinia region (on the basis of the MEISAR Project [3]) and of the province of Brescia (based on the new Provincial Plan of Sand and Gravel Quarries, ref. [4]). The analysis is based on the following factors: geographical 
characteristics; building volumes built per year; NA and RA market and incentives for use of RA. The clustering model extrapolated from the MEISAR project will also report the relative radii of influence. The geospatial representation was carried out in a GIS environment using network analysis tools in order to identify mature territorial contexts of circular economy. The paper is developed in the following paragraphs: Assessment of the territorial offer of NA and RA (Context analysis and Circular Cluster Distribution), discussions and conclusions.

\section{Assessment of the territorial offer of NA and RA}

The two case studies present significant similar aspects (demographic dimensions, production volumes, etc.) and different aspects (geographic and urban), which make the comparison of the NA and AR offer and the related analysis representative.

\subsection{Context analysis}

The province of Brescia extends for 4,784 square kilometers, includes 205 municipalities, $45 \%$ of which are located in the mountain area, $34 \%$ in the plains and $19 \%$ in the hills; it has a population (2021) of 1,246,325 inhabitants [5] with an average density of 260 inhab / $\mathrm{kmq}$. The island region of Sardinia, on the other hand, is much larger than the province of Brescia (almost 5 times greater with 24,089 sq km), it includes 377 municipalities and 8 provinces; it has a population of 1,653,135 inhabitants [5] therefore comparable to that of the province of Brescia, but with a much lower density (69 inhabitants / sq km).

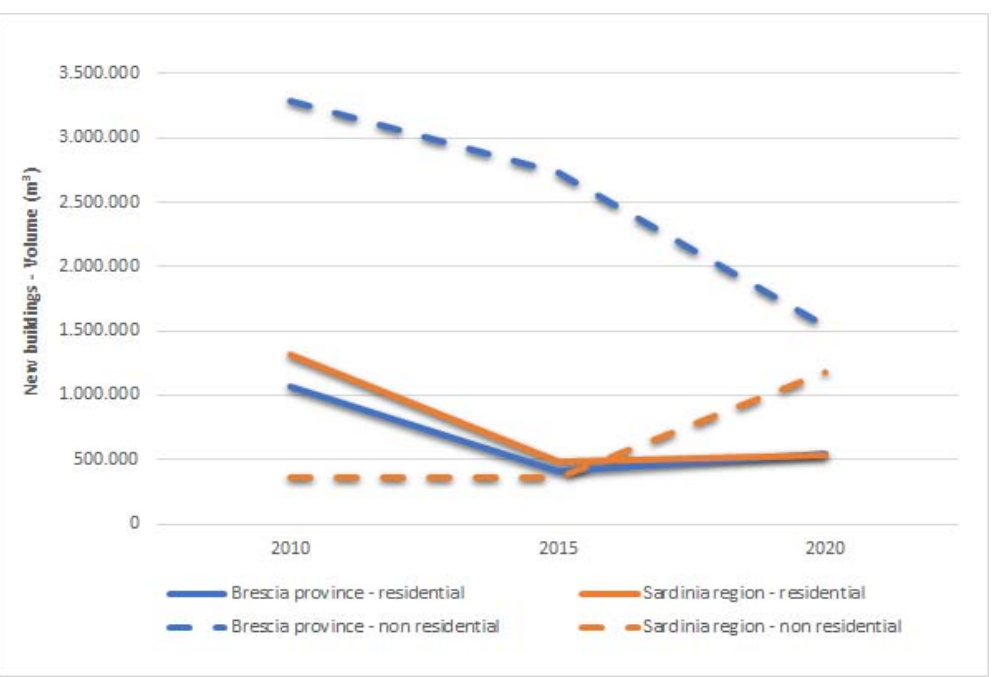

Fig. 1 - New Building Volumes (residential and non residential buildings) in Brescia province and in Sardinia region, 2010,2015 and 2020. (Author: Richiedei A., source: [6]

As regards the demand for aggregates, it is possible to use a parameter that approximates the need for use: the annual volume of residential and non-residential buildings. This parameter is also used for the pre-dimensioning of quarry plans (in Lombardy). In particular, from figure (Fig. 1) it is possible to see how the volumes built in Sardinia and in the province of Brescia are comparable with the exception of non-residential buildings in 2010 and 2015 [6]. The NA and AR market are also different: in Sardinia the market can be defined as closed as the island condition limits the movement of materials, while in the province of Brescia the market can be considered open for opposite reasons and characterized by a articulated presence of type mobility networks (long and short). The Sardinia region provides incentives for the use of ARs, while this does not happen in the province of Brescia. 


\subsection{Circular Cluster Distribution}

As a result of the MEISAR Project, a georeferenced database of activities related to the extraction, processing and disposal of materials related to the construction process was built [1]. In the two case studies it is possible, with the same methodology proposed for the MAISER Map, identifying potential clusters (Circular Cluster Distribution) for NA and RA. In particular, from the MEISAR Project database, available for the whole region, it is possible to identify clusters based on the coexistence of four types of proximity facilities to support circular economy: extraction of natural resources (quarries); recovery (recovery plants), concrete production (batching plants); landfills of construction and demolition waste $(\mathrm{CDW})$. The areas of influence of the clusters are strongly influenced by the limits of transportability resulting from the low unit cost of CDW, RA and NA [7, 8, 9]. Another limit, of a technical nature, relates to the transportability of ready-mixed concrete within $30 \mathrm{~km}$ from the place of production in order not to jeopardize both its technical performance and its workability characteristics. The areas of influence of the circular clusters can therefore be defined as $30 \mathrm{~km}$. The geospatial analysis of the case studies: clusters and their areas of influence (isodistance) are shown in Figure 2.

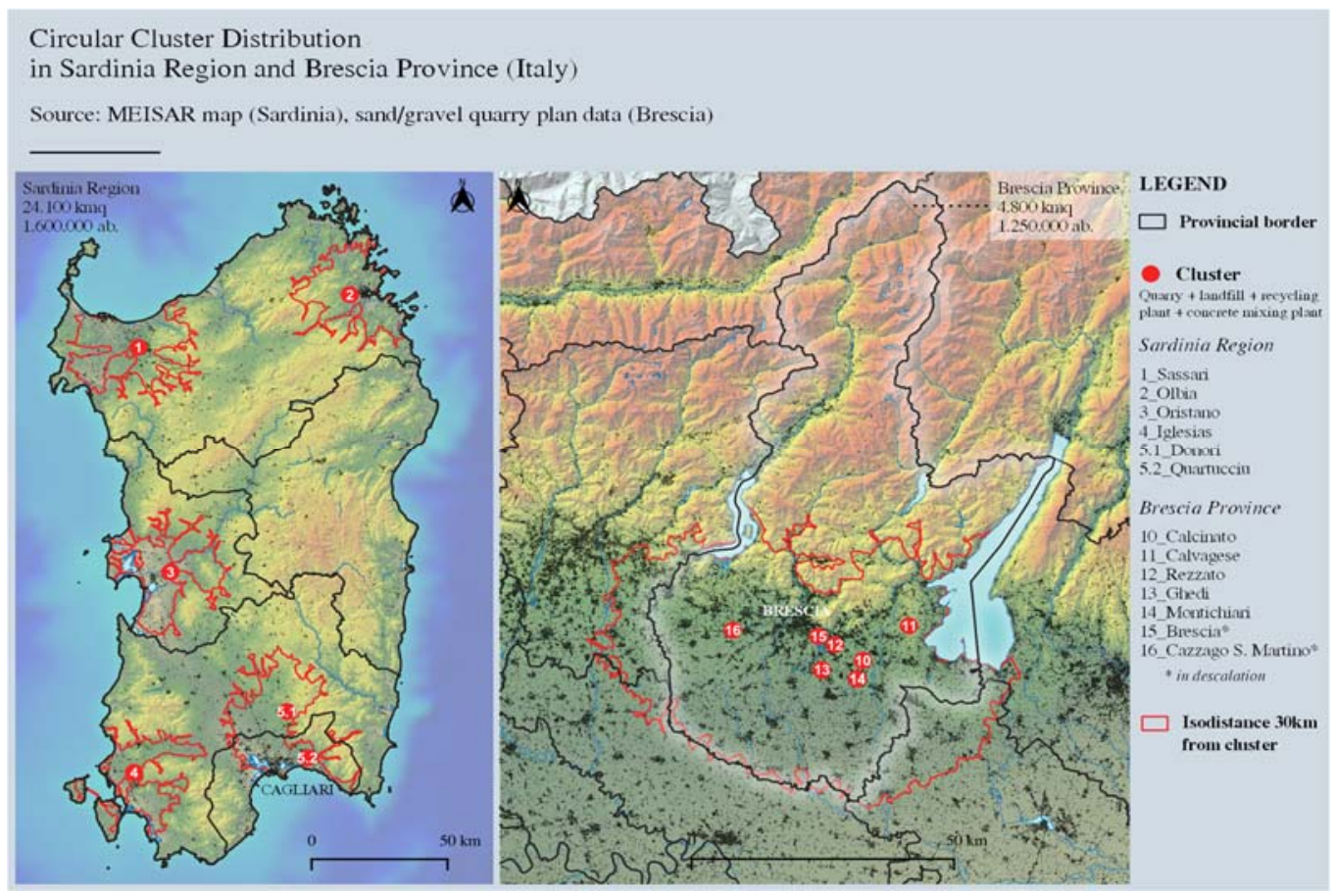

Figure 2. Circular Cluster Distribution (Author: Pavesi, F.C., sources: MEISAR map; Sand/gravel Quarry Plan data, 2021)

\section{Discussions}

The analysis shows how the cluster that gathers all 4 facilities is present in both case studies. This type of cluster is the most important for the circular economy, in fact all the functions are located in a limited place. This cluster is an invariant of both the closed market and the open market. Furthermore, the materials considered (CDW, NA and RA) have characteristics (technical and weight) that significantly influence transport costs, the geographic proximity of the various facilities was evaluated as a winning element for circular economy processes. In both case studies, the clusters are in 'mutual' and 'absolute' proximity to major densely populated urban centers. In fact, these urban centers represent both the outlet markets for concrete produced with RA and the places where resources are found (CDW) for the production of RA. For the Province of Brescia it is also possible to identify partial clusters (without landfill or concrete mixing plant) which, however, 
make it possible to respond to a greater complexity of the territorial system to which the interprovincial demand for concrete is linked. Finally, the clusters are localized in correspondence with the larger and densely populated urban centers, thus leaving vast areas with low population density uncovered.

\section{Conclusions}

The two case studies show an overall maturity which, however, has intrinsic and extrinsic criticalities. Among the main intrinsic criticalities: limit of the circularity distance equal to $30 \mathrm{~km}$ resulting in a non-homogeneous circular economy in the territory. Among the main extrinsic criticalities: unstable construction market (residencial and not residencial) and the improvement of the performance of transport infrastructures with a high demand for mobility. These intrinsic and extrinsic characteristics confirm how the processes of circular economy develop (origin and destination) mainly in urban areas with a high population density and in proximity to performing transport infrastructures. This condition, winning from an economic point of view, is often perceived as disadvantageous by the population due to the concentration of functions potentially impacting the environment in the same territory (NIMBY syndrome). In reality, the proximity between functions can allow a better coordinated monitoring of the environmental matrices and to undertake any corrective actions considering the circularity of the process. In summary, the circular economy processes deriving from CDWs are predominantly urban. Circularity in the extra-urban therefore requires incentive policies in order to be competitive with respect to the linear (current prevailing economy) economic processes of CDWs. In this sense, we intend to develop research, that is to quantitatively assess the intermediate maturity levels of extra-urban areas and then identify strategies for their relative improvement of the circular performance [10].

\section{References}

1. Istituto Superiore per la Protezione e la Ricerca Ambientale - ISPRA (2020). Rapporto Rifiuti Speciali 2021. https://www.isprambiente.gov.it/files2021/pubblicazioni/rapporti/rapportorifiutispeciali_ed-2021_n$\underline{344 \text { versioneintegrale.pdf }}$

2. Collivignarelli, M.C.; Cillari, G.; Ricciardi, P.; Miino, M.C.; Torretta, V.; Rada, E.C.; Abbà, A. The Production of Sustainable Concrete with the Use of Alternative Aggregates: A Review. Sustainability 2020, 12, 7903. https://doi.org/10.3390/su12197903

3. Balletto, G., Borruso, G., Mei, G., \& Milesi, A. (2021). Recycled aggregates in constructions. A case of circular economy in Sardinia (Italy). TeMA - Journal of Land Use, Mobility and Environment, 14(1), 51-68. https://doi.org/10.6092/1970-9870/7354

4. Pavesi, F.C.; Richiedei, A.; Pezzagno, M. Advanced Modelling Tools to Support Planning for Sand/Gravel Quarries. Sustainability 2021, 13, 6380. https://doi.org/10.3390/su13116380

5. ISTAT, 2021 - GeoDemoistat. Available online: https://demo.istat.it/ (accessed on 24/11/2021).

6. ISTAT, 2020 - Permessi di costruire. Available online: https://www.istat.it/it/archivio/permessi+di+costruire?page=1 (accessed on 24/11/2021).

7. Balletto G., Borruso G., Mei G., Milesi A. (2021) Circular economy in construction. A case study in Sardinia (Italy). ASCE Urban Planning and Development Division Journal 146. DOI:10.1061/(ASCE) UP.1943-5444.0000715

8. Balletto G., Borruso G., Mei G., (2019) Location Theory and Circular Economy. Demolition, Constructions and Spatial Organization of Firms-An Applied Model to Sardinia Region. The Case Study of the New Cagliari Stadium. In International Conference on Computational Science and Its Applications (pp. 535-550). Springer, Cham. ISBN 978-3-030-24310-4ISBN 978-3-03024311-1 (eBook) - https://doi.org/10.1007/978-3-030-24311-1.

9. Balletto, G., Mei, G., \& Garau, C. (2015). Relationship between quarry activity and municipal spatial planning: a possible mediation for the case of Sardinia, Italy. Sustainability, 7(12), 16148-16163. https://doi.org/10.3390/su71215801

10. Bolger, K., \& Doyon, A. (2019). Circular cities: exploring local government strategies to facilitate a circular economy. European planning studies, 27(11), 2184-2205. DOI 10.1080/09654313.2019.1642854 